\title{
The Influence of Nanostructured Hydroxyapatite Surface in the Early Stages of Osseointegration: A Multiparameter Animal Study in Low-Density
} \section{Bone}

This article was published in the following Dove Press journal:

International Journal of Nanomedicine

\author{
Suelen Cristina \\ Sartoretto (iD) ${ }^{1-4}$ \\ Jose Calasans-Maia (iD ${ }^{5}$ \\ Rodrigo Resende (iD $2,4,6$ \\ Eduardo Câmara ${ }^{3}$ \\ Bruna Ghiraldini $(\mathbb{D})^{7}$ \\ Fabio Jose Barbosa Bezerra $\mathbb{D D}^{8}$ \\ Jose Mauro Granjeiro iD ${ }^{4,9}$ \\ Monica Diuana Calasans- \\ Maia (iD) 4,6 \\ 'Oral Surgery Department, Universidade \\ Veiga de Almeida, Rio de Janeiro, RJ, Brazil; \\ ${ }^{2}$ Oral Surgery Department, Universidade \\ Iguaçu, Nova Iguaçu, RJ, Brazil; ${ }^{3}$ Post- \\ Graduation Program in Dentistry, \\ Universidade Veiga de Almeida, Rio de \\ Janeiro, RJ, Brazil; ${ }^{4}$ Clinical Research \\ Laboratory, Dentistry School, \\ Universidade Federal Fluminense, Niteroi, \\ RJ, Brazil; ${ }^{5}$ Orthodontics Department, \\ Dentistry School, Universidade Federal \\ Fluminense, Niteroi, RJ, Brazil; ${ }^{6}$ Oral \\ Surgery Department, Universidade \\ Federal Fluminense, Niteroi, RJ, Brazil; \\ ${ }^{7}$ Dental Research Division, Dentistry \\ School, Universidade Paulista, São Paulo, \\ SP, Brazil; ${ }^{8}$ Laboratory of Bioassays and \\ Cell Dynamics, IBB-UNESP, Botucatu, \\ Brazil; ' National Institute of Metrology, \\ Quality and Technology (INMETRO), \\ Duque de Caxias, RJ, Brazil
}

Correspondence: Monica Diuana Calasans-Maia; Jose Mauro Granjeiro Universidade Federal Fluminense, Rua Mario Santos Braga, 28/4 Floor, Niteroi, RJ, Brazil

Tel +55 2l 98I53-5884

Email monicacalasansmaia@gmail.com; jmgranjeiro@gmail.com
Background and Objective: The success rates of dental implants in low-density bone have been reported as a challenge, especially for early or immediate loading in the maxilla posterior area. Nanoscale architecture affects the roughness, surface area, surface energy of the implant and can enhance osseointegration. This study aimed to evaluate the implantsurface topography and biomechanical, histomorphometric, and histological bone responses to a new nanostructured hydroxyapatite surface placed in the iliac crest of sheep.

Methods: Ten female sheep (2-4 years) received 30 implants (n=10/group): HAnano ${ }^{\circledR}$ coated (Epikut Plus ${ }^{\circledR}$, S.I.N. Implant System, Sao Paulo, SP, Brazil), SLActive (BLX ${ }^{\circledR}$, Straumann, Basel, Switzerland), and TiUnite (NobelActive ${ }^{\circledR}$, Nobel Biocare, Göteborg, Sweden) surfaces. Scanning electron microscopy with energy-dispersive spectroscopy evaluated the implant surface topography, the insertion torque value, and resonance frequency analysis evaluated the primary stability, bone-implant contact, and bone-area fraction occupancy were evaluated after 14 and 28 days after implant placement.

Results: The surface morphology was considerably comparable between the implant groups'; however, the TiUnite ${ }^{\circledR}$ group presented a remarkable different surface. The SLActive ${ }^{\mathbb{B}}$ and TiUnite ${ }^{\circledR}$ groups presented an insertion torque average of $74( \pm 8.9) \mathrm{N} / \mathrm{cm}$ that was similar to that of HAnano ${ }^{\circledR} 72( \pm 8.3) \mathrm{N} / \mathrm{cm}(\mathrm{p}>0.05)$. The resonance frequency evaluated with Osstell ${ }^{\circledR} /$ SmartPeg $\left.{ }^{(}\right)$or Penguin ${ }^{(} /$MulTipeg $^{(\mathbb{B}}$ showed similar results when assessing implants from the same group. BIC and BAFO significantly increased $(p<0.05)$ throughout the experimental periods to all groups, but BIC and BAFO values were similar among the implants at the same time point. After 4 weeks, bone-implant contact was higher than $80 \%$ of the total length analyzed. New bone occupies around $60 \%$ of analyzed area around the implants.

Conclusion: HAnano ${ }^{\circledR}$ coated surface promoted comparable osseointegration as SLActive and TiUnite in the sheep model. The three tested surfaces showed comparable osseointegration at the early stages of low-density bone repair in the sheep model.

Keywords: osseointegration, dental implant surface, nanotechnology, hydroxyapatite, sheep, bone response

\section{Introduction}

Dental implantation in partial or totally edentulous patients is a predictable treatment with high rates of long-term success, ${ }^{1}$ however, early osseointegration is still considered a challenge in areas with the most trabeculated bone (bone type IV) ${ }^{2}$ 
together with lower-density and thinner cortical bone, which is generally considered less suitable for supporting dental implants. In recent years, implant-surface technologies with micro- to nanotopography, chemical compositions, macro-scale implant designs, loading protocols, and new surgical procedures have been introduced to improve the osseointegration and reduce the treatment term, allowing immediate or early functional loading in patients with reduced bone density. ${ }^{3-5}$

The implant's surface is critical for guaranteeing dental implants' osseointegration, preferably in the short term. Various approaches to improve these surfaces have been studied, including mechanical (eg, machining, grinding, polishing, blasting), chemical (eg, acid treatment, alkali treatment, hydrogen peroxide, and anodic oxidation), and physical (eg, plasma and flame spray, ion beam implantation $)^{6}$ techniques.

Calcium phosphate has been widely used as a bone substitute; ${ }^{7,8}$ dental-implant coating; ${ }^{9}$ and carrier for proteins, ${ }^{10}$ growth factors, ${ }^{11}$ and drugs ${ }^{12-14}$ due to its similarity to bone tissue's mineral content and suitable cellattachment capacity. Among the calcium phosphates, hydroxyapatite in particular has been favored given its biocompatibility, safety, predictability, unlimited availability, lower morbidity for the patient, and cost-effectiveness, which offer significant advantages and make it a good choice for dental-implant coatings. ${ }^{15}$ The use of nanostructured hydroxyapatite when coating titanium-implant surfaces improves the characteristics of the implant surface, increases the strength of the bond between titanium and bone, enhances the rate of osseointegration, and reduces the length of the treatment period, especially in patients whose bone quality is poor. 9

Early experiences with coatings applied to dental implants in the 1990s failed for various reasons, including a detachment of the hydroxyapatite coating and dissolution of the detached HA. ${ }^{16,17}$ However, more recently, coating methods have been improved and ion-sputtering or thermal-plasma treatment has been successfully applied. ${ }^{18,19}$ This has resulted in more durable coatings that adhere better to the titanium substrate and, therefore, show more significant promise for clinical use mainly in the posterior area of maxilla and immediate implant installation. The demands from specific locations suggest that coated implants might be necessary to ensure better clinical results, renewing the interest in coated dental implants.

Topographical modifications to dental-implant surfaces can vary from millimeter-wide grooves to nano-sized structures. $^{20}$ The nanometric modifications on the surface of osseointegradable implants are made based on sizeequivalent arrangements present in bone, which result in a well-organized, three-dimensional nanotopography. Besides, the biomolecules and cells involved in the early healing phase after implant installation will interact at the nanometer level. ${ }^{21-23}$

There is a continuous increase in the effort to develop novel and bioactive surfaces to reduce the osseointegration period in low-density bone is ongoing. Since current coatings have not yet shown the necessary levels of improvement for bone with low rates of remodeling and in the early time, new implant surfaces have been researched and developed. This study aimed to compare the bone response of the HAnano ${ }^{\circledR}$ coated surface (S.I.N. Implant System, Sao Paulo, Brazil) to the well-known hydrophilic surfaces such as the SLActive ${ }^{\circledR}$ (Straumann, Basel, Switzerland) and TiUnite $^{\circledR}$ (Nobel Biocare, Gothenburg, Sweden) through histomorphometric analysis of bone-implant contact (BIC) and bone area fraction occupancy (BAFO) in sheep model of low-density bone.

\section{Materials and Methods Implants and Surface Characteristics}

Thirty titanium dental implants $(3.5 \mathrm{~mm}$ in diameter and $10 \mathrm{~mm}$ in length) with the following three different surface modifications were used ( $\mathrm{n}=10 /$ group): the HAnano group (Epikut Plus ${ }^{\circledR}$; Sistema de Implante Nacional SA, São Paulo, Brazil) included implants with a nano-sized crystalline hydroxyapatite coating; the SLActive group $\left(\right.$ BLX $^{\circledR}$; Straumann, Basel, Switzerland) included implants with a hydrophilic sandblasted and acid-etched titanium surface; and the TiUnite group (NobelActive ${ }^{\circledR}$; Nobel Biocare, Göteborg, Sweden) included implants with a highly crystalline and phosphate-enriched anodized titanium-oxide surface.

High-resolution scanning electron microscopy images obtained with FEI-QUANTA 450 (Thermo Fisher Scientific, Waltham, MA, USA) revealed the surface topography of the implants, one sample per group, at an accelerating voltage of $10 \mathrm{kV}$; focal width of 3.0 ; and magnifications of $50 \times, 3000 \times$, and $15,000 \times$. Energy-dispersive X-ray spectroscopy analysis determined each surface's chemical composition at an acceleration voltage of $20 \mathrm{kV}$ and focal width of 40 using an EDAX detector equipped with a dual-beam electron microscope (AMETEK Materials Analysis Division, Mahwah, NJ, 
USA) and the Genesis software program (EDAX, LLC, Mahwah, NJ, USA).

\section{Animal Model}

This study report followed the Animal Research: Reporting of in vivo Experiments (ARRIVE) ${ }^{24}$ and Planning Research and Experimental Procedures on Animals: Recommendations for Excellence (PREPARE $^{25}$ guidelines where appropriate. Ten adult female Santa Ines sheep were used for this study, with an average age of three years (2-4 years) and an average weight of $37.05 \mathrm{~kg}$ (31-42 kg). To minimize the effects of subjective bias when allocating animals to treatment, the animals were randomly allocated into two experimental periods of two and four weeks using the coin-toss method of randomization. Animal experiments and breeding occurred under conditions in compliance with the National Institutes for Health Guide for the Care and Use of Laboratory Animals ${ }^{26}$ and relevant Brazilian legislation on animal use. ${ }^{27} \mathrm{An}$ experienced veterinarian conducted nutritional recommendations, animal care, and fasting in pre- and postoperative animals. The Ethics Committee for Animal Use of Fluminense Federal University in Cachoeira de Macacu, Rio de Janeiro, Brazil approved the protocol of this study (CEUA \# 9,531,061,119). The animal experiments occurred during the first half of 2020 . None of the animals were euthanized after the end of the study in compliance with the guidelines of the 3Rs Program ("Reduction, Refinement, and Replacement), whose objective is to reduce the number of animals used during experimentation, minimize pain and discomfort, and avoid euthanasia at the end of experimentation. ${ }^{28}$ All animals were immunized against common diseases for sheep and were submitted to tests to ensure good physical condition. The Veterinarian School Farm of Fluminense Federal University harbored the animals used in this study in a fenced semi-extensive system with native fodder and signal grass (Brachiaria humidicola and Brachiaria decumbens). In the preoperative period, the animals received food composed of the pastures above and, during the postoperative period, in addition to the mentioned pastures, nutritional supplementation proper for sheep. Salt mineral water ad libitum was available during the entire experimental period.

Aiming to reduce preoperative stress levels in the animals, the veterinarian moved the sheep two weeks before the surgery from the breeding site to the research center for adequate acclimatization. ${ }^{29}$ The animals were fasted for eight hours before the surgery.

\section{Sample-Size Calculation}

A significant effect of $15 \%$ or more 28 days after surgery in the BIC (primary outcome) would be of interest. Considering previous rates ${ }^{30}$ for BIC at 28 days postsurgery in the control group and intervention group of $66.5 \%$ and $76.5 \%$, respectively, with a two-sided significance of 0.05 and a power of 0.8 , this study required a total of five sheep. $^{31,32}$

\section{Surgical Model}

The pelvic animal model was used for all experiments according to previous research..$^{30,33-36}$ The cranial part of each animal's right iliac wing $(n=5 /$ group) received all implants (Figure 1). Five implants were installed in each animal, but only three were used for this study. The other two were used for another study.

\section{Anesthetics and Analgesia}

The animals were premedicated with $0.05 \mathrm{mg} / \mathrm{kg}$ of acepromazine intravenously $\left(\right.$ Acepran $^{\circledR}$; Vetnil, Louveira, São Paulo, Brazil), $0.2 \mathrm{mg} / \mathrm{kg}$ of diazepam intravenously (Teuto, Anapolis, Goias, Brazil) and $0.4 \mathrm{mg} / \mathrm{kg}$ of morphine intramuscularly (Dimorf $^{\circledR}$; Cristalia, Itapira, Sao Paulo, Brazil). After 20 minutes, with the animals exhibiting no response to pain, cephalic-vein cannulation was initiated for the administration of $5 \mathrm{~mL} / \mathrm{kg} / \mathrm{h}$ of lactated Ringer's solution intravenously (Baxter Hospitalar LTDA; Sao Paulo, São Paulo, Brazil). Anesthesia was induced with $4 \mathrm{mg} / \mathrm{kg}$ of propofol intravenously (Baxter Hospitalar LTDA; São Paulo, São Paulo, Brazil) and maintained using 1\% isoflurane (Cristalia, Itapira, Sao Paulo, Brazil) following orotracheal intubation. Meanwhile, 4 $\mathrm{mg} / \mathrm{kg}$ of lidocaine (Xylestesin ${ }^{\mathrm{TM}}$; Cristalia, Itapira, Sao Paulo, Brazil) and $0.1 \mathrm{mg} / \mathrm{kg}$ of morphine $\left(\right.$ Dimorf $^{\mathbb{B}}$; Cristalia, Itapira, Sao Paulo, Brazil) was used to block the epidural. A very experienced veterinarian managed the anesthesia and supervised all procedures throughout the surgery.

\section{Surgical Procedures}

The right side of the iliac crest was initially shaved with a razor blade, with subsequent application of an antiseptic chlorhexidine $0.5 \%$ solution. An incision of approximately $5 \mathrm{~cm}$ in length was made over the region of the animal's iliac wing (right side) using scalpel handle no. 3 (Bard 

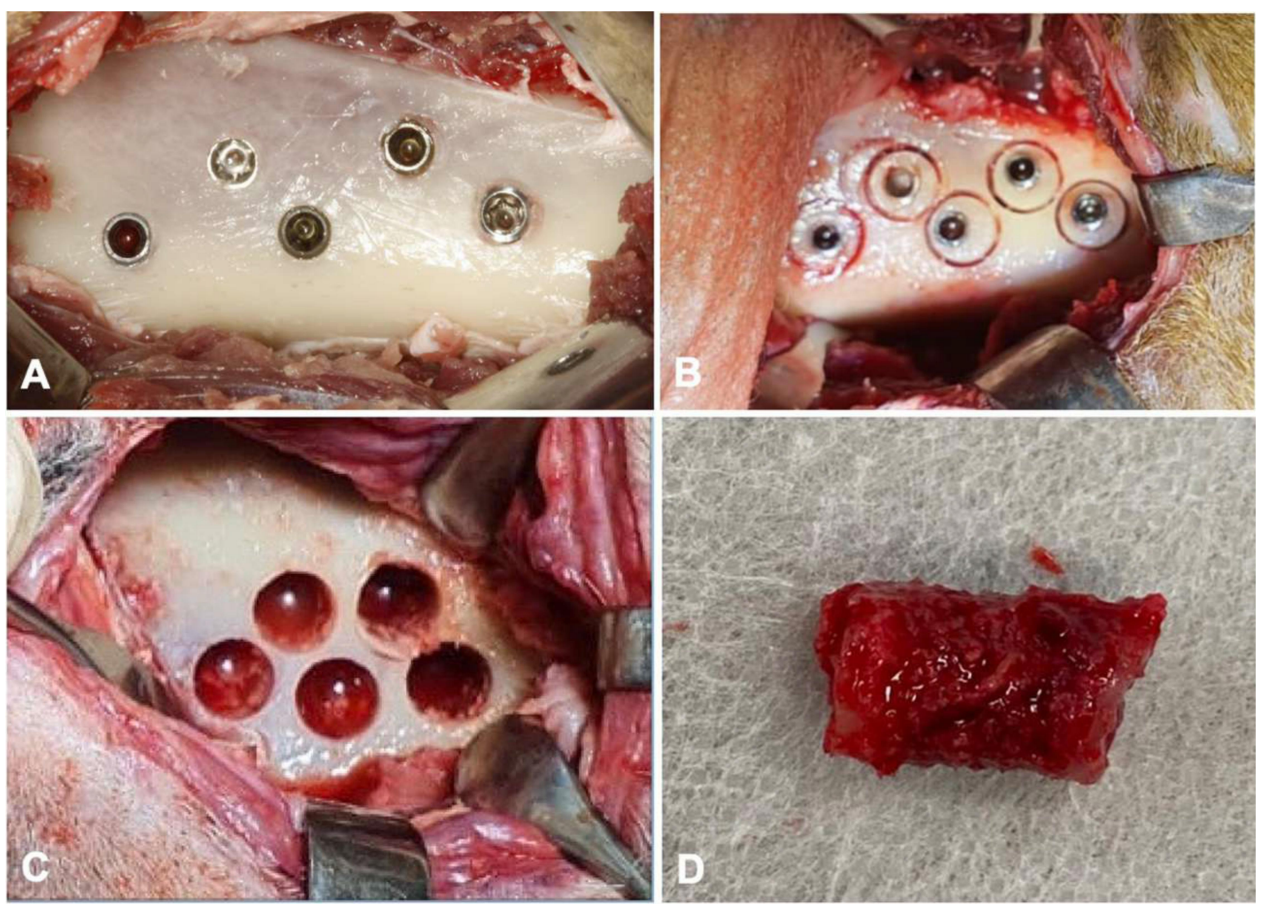

Figure I Surgical procedures for implant's installation of the 5 implants. (A) Implants installed in the iliac crest with a minimum distance of 5 mm between each implant; (B) after 2 and 4 weeks, the implants were trephined with a trephine drill (internal diameter $=5 \mathrm{~mm}$ ) to remove the bone block containing the implant; (C) bone defects after the removal of the bone blocks and (D) bone block trephined with implant inside.

Parker $^{\circledR}$, Aspen Surgical, Caledonia, MI, USA) and blade no. 15 (Solidor ${ }^{\circledR}$; Lamedid, Osasco, São Paulo, SP, Brazil). After the incision was made, the skin, muscle, and periosteum were detached for bone perforations. The sequence of burs recommended by the manufacturer was used in low rotation $(1200 \mathrm{rpm})$, with profuse irrigation with a $0.9 \%$ sodium chloride solution (Darrow Laboratórios SA, Rio de Janeiro, RJ, Brazil) to avoid tissue necrosis due to overheating. Five implants were installed (one for each group and two for another study) with the aid of a counter-angle coupled to a surgical electric micromotor (BLM 600 plus; K Driller, São Paulo, Brazil) with the capacity for $24 \mathrm{rpm}$. The implants were placed in the first sheep after randomly selecting the position for each using the sealed-envelope method. In the next sheep, the implant position was rotated clockwise, and all five implants were placed in different locations. At the end, no implant used the same implantation site as another. The interimplant distance was at least $5 \mathrm{~mm}$. The surgeons evaluated the resonance frequency analysis (RFA) for all implants using Osstell ${ }^{\circledR}$ and Penguin ${ }^{\circledR}$ with magnetic transducers SmartPeg ${ }^{\circledR} \quad$ (Integration Diagnostics, Savedalen, Sweden) and MulTipeg ${ }^{\circledR}$ (Penguin Integration Diagnostics, Göteborg, Sweden), respectively.
Finally, absorbable sutures (Vicryl 4-0; Ethicon, Inc., Somerville, NJ, USA) were used to close the repositioned periosteal flap and skin (5.0 nylon sutures; Ethicon ${ }^{\circledR}$; Somerville, NJ, USA). The operative wounds were left uncovered and the surgery region received no external immobilization.

\section{Implant Stability Measurements}

The surgeons carried out the RFA with the Osstell ${ }^{\circledR}$ ISQ and Penguin ${ }^{\circledR}$ RFA device. MulTipegs ${ }^{\circledR}$ magnetic transducers were mounted on each implant and tightened with hand pressure using the metallic screwdriver recommended by the manufacturer. The probe of the Penguin ${ }^{\circledR}$ RFA was held $1 \mathrm{~mm}$ from the MulTipeg ${ }^{\circledR}$ and the implant stability (ISQ) was registered on the digital display of the instrument for each implant. Three consecutive measurements from the lateral direction were recorded. The authors considered the mean of the three ISQ values to be the final ISQ value of each implant.

Also, the RFA measurements were collected with the Osstell ${ }^{\circledR}$ ISQ device using the SmartPeg ${ }^{\circledR}$ system and the plastic screwdriver supplied by the manufacturer. The authors considered the mean of the three ISQ values as the final ISQ of each implant. 


\section{Postoperative Care}

All animals received antibiotic therapy by intramuscular injection of $0.1 \mathrm{~mL} / \mathrm{kg}$ of oxytetracycline (Terramicina ${ }^{\circledR}$; Pfizer, New York, NY, USA) every 48 hours for three days. Additionally, $4 \mathrm{mg} / \mathrm{kg}$ of Tramal $^{\circledR}$ (Pfizer, New York, NY, USA) and $0.5 \mathrm{mg} / \mathrm{kg}$ of the anti-inflammatory meloxicam (Meloxivet ${ }^{\mathbb{R}}$; Duprat, Rio de Janeiro, RJ, Brazil) were given over five days. Oxytetracycline spray with hydrocortisone was used daily at the wound site (Terra-Cortril $^{\circledR}$ Spray; Zoetis, São Paulo, SP, Brazil). Zinc oxide ointment with cresylic acid was applied (Unguento Chemitec ${ }^{\circledR}$; Chemitec, São Paulo, SP, Brazil) together with silver spray (Aerocid Total ${ }^{\circledR}$; Agener União, Araçoiaba da Serra, SP, Brazil) to support healing and the prevention of insects.

\section{Histological Preparation}

After two and four weeks, the animals were re-operated on to remove the implants with a 5-mm internal diameter trephine drill (S.I.N. Implant System, São Paulo, SP, Brazil). The surgical procedures followed the protocol reported above and all sheep were subsequently returned to the farm, where they completely recovered. The samples containing bone and implants were fixed in 4\% neutral-buffered formalin solution for 48 hours and then dehydrated in ascending alcohol solutions of $60 \%, 70 \%, 90 \%$, and $100 \%$. Thereafter, infiltration with a light-curing resin (Technovit 7200; Kulzer \& Co., Wehrheim, Germany) was performed according to the manufacturer's instructions. The samples were then embedded in the same resin, cut in the mid-axial and apical-coronal planes using a macro-scale cutting and grinding technique (Exakt 310 CP series; Exakt Apparatebau, Norderstedt, Germany), and ground and polished to a final thickness of 30 to $40 \mu \mathrm{m}$. Toluidine blue stained the samples to differentiate newly formed bone, and acid fuchsin were used to contrast the background. Light microscopy at $10 \times$ and $20 \times$ magnifications (Olympus BX43; Olympus Corporation, Tokyo, Japan) supported the analysis of the slices, with images acquired with the cellSens software (Olympus Corporation, Tokyo, Japan), and polarization light microscopy (Axioplan; Carl Zeiss AG, Oberkochen, Germany) enabling the visualization of the general orientation of collagen fibers.

\section{Histomorphometry Analysis}

From each slide obtained by histological processing, photomicrographs with $10 \times$ magnification were captured in sequenced fields to scan and reconstruct the total area of the implant and adjacent bone (Figure 2A). Following the reconstruction of all images, the area of interest was determined and drawn, in the vertical direction, from the first thread of the implant to the beginning of the fourth thread (Figure 2B). This vertical delimitation was used to determine the BIC value, which was later transformed into a percentage. The implant-profile design was then duplicated and aligned at a distance of $270 \mu \mathrm{m}$ in the horizontal plane, thus completing the total area of interest (Figure 2C). The bone area fraction occupancy was determined manually with Image J (National Institutes of Health, Bethesda, MD, USA), which was later transformed into a percentage (Figure 2D).

\section{Statistical Analysis}

The data for RFA using Osstell ${ }^{\circledR}$ and Penguin ${ }^{\circledR}$ device and insertion torque values (IVT) did not pass the Shapiro-Wilk normality test; the $\log$ (ISQ) and log (IVT) for HAnano ${ }^{\circledR}$, SLActive $^{\circledR}$, and TiUnite ${ }^{\circledR}$ was evaluated using the one-way ANOVA test and Tukey's posttest $(\mathrm{p}<0.05)$. The Student's $t$-test compared the data obtained by Osstell ${ }^{\circledR} / \mathrm{SmartPeg}^{\circledR}$ and Penguin ${ }^{\circledR} /$ MultiPeg $^{\circledR}$ for each implant surface, considering $\alpha=0.05$.

For the evaluation of BIC and BAFO of the various surfaces in the same experimental period, the One-Way ANOVA parametric test and Tukey's posttest $(\mathrm{p}<0.05)$ were applied. The Student's $t$-test $(\mathrm{p}<0.05)$ evaluated the significance of BIC and BAFO of the same surface and at different experimental periods. The values are presented as mean \pm confidence interval $(\mathrm{n}=5$ animals per group/experimental period). The Prism Graph Pad 8.3 ${ }^{\circledR}$ software (Inc. La Jolla, California, USA) enabled all the statistical analysis.

\section{Results \\ Surface Characterization}

Scanning electron microscopy micrographs of the implant's surface revealed the samples' textured microstructures and topography (Figure 3). The observed surface texture at intermediate $(3000 \times)$ and high $(15,000 \times)$ magnifications appeared considerably comparable in terms of the surface morphology between the implant groups; however, group TiUnite ${ }^{\circledR}$ exhibited a different remarkably surface morphology. Figure $3 \mathrm{~A}$ and B present an example of a typical nano-HA surface with a well-defined micro-scale rough surface. The sandblasting and etched process's micro-scale rough surface texture can be seen in Figure $3 \mathrm{C}$ and $\mathrm{D}\left(\right.$ SLActive $\left.^{\circledR}\right)$. The implants treated with the anodic plasma-chemical surface-modification method is shown in Figure 3E and F; the surface layer is composed of 

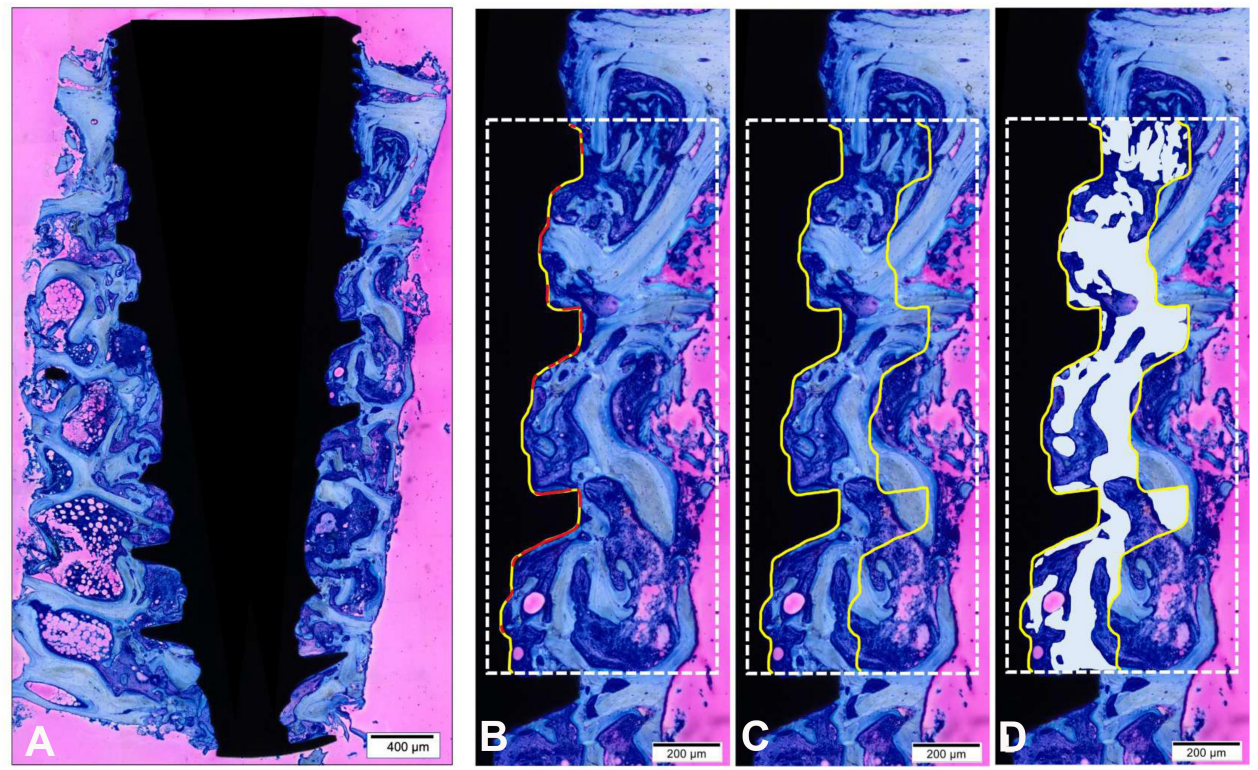

Figure 2 Histomorphometry for bone-implant contact and (BIC) and bone area formation (BAFO) analysis. (A) Histological reconstruction of the implant and adjacent bone area; (B) determination of the line of interest for BIC; in the long implant axis, the implant profile design was drawn from the first thread of the implant to the beginning of the fourth thread (yellow line) and direct bone-implant contact (red line); (C) determination of the area of interest for BAFO. An identical line of implant profile design was duplicate and aligned at a distance of $270 \mu \mathrm{m}$ at the horizontal plane (total area); (D) the bone area formation (BAFO) manually determinates for posterior analysis (total area/BAFO) (\%). Stain: Toluidine Blue and Acid Fuchsin stained. Scale bar: (A) $400 \mu \mathrm{m} ;($ B,C and D) $200 \mu \mathrm{m}$.

small craters with holes in the center $\left(\right.$ TiUnite $\left.^{\circledR}\right)$. Energydispersive spectroscopy revealed the presence of calcium only in the nano-HA group and that of sodium only in the SLActive ${ }^{\circledR}$ group. Titanium, vanadium, and phosphorus peaks were observed in all groups (Supplementary Figure 1).

\section{Resonance Frequency Measurements}

The resonance frequency analysis occurred with the following devices and transducers Osstell ${ }^{\circledR} /$ SmartPeg $^{\circledR}$, and Penguin ${ }^{\circledR} /$ MultiPeg $^{\circledR}$. Figure 4 shows the log values of ISQ obtained from the resonance frequency analysis of HAnano $^{\circledR}$, SLActive ${ }^{\circledR}$, and TiUnite ${ }^{\circledR}$. The Penguin ${ }^{\circledR} /$ MultiPeg $^{\circledR}$ analysis showed significantly higher resonance frequency values than the Osstell/Smart Peg on all implants $(p<0.05)$. However, no significant ISQ difference occurred between the implants under the same device, Osstell $^{\circledR} /$ SmartPeg $^{\circledR} \quad$ or Penguin $^{\circledR} /$ MultiPeg $^{\circledR} \quad(p<0.05)$ Supplementary Table 1.

\section{Implant Torque Value (ITV)}

There was no statistical difference among the tested implants surfaces $\left(\right.$ HAnano $^{\circledR}$, SLActive ${ }^{\circledR}$, and TiUnite ${ }^{\circledR}$ ) regarding the insertion torque, and all groups presented a mean insertion torque between 72 and 74 N/cm (Figure 5) (Supplementary Table 1).

\section{In vivo Study}

Anesthesia, surgical intervention, and implant placement were completed uneventfully. All animals recovered quickly and could walk immediately after surgery. All animals gained weight after surgery except for one sheep that lost almost $10 \%$ of its initial weight 28 days after surgery. Still, no changes were observed in the histological results, so the weight loss probably did not impact the biological effects. No case of superficial nor deep infection happened. All animals were furnished daily with regular feed and water intake until the end of the study. All implants were able to be placed according to the intended technique and distribution. No implant exhibited clinical mobility, bone loss, or infection.

\section{Histological Evaluation}

Descriptive qualitative microscopic evaluation of the nondecalcified samples demonstrated time-dependent new bone formation in all groups, visible by way of blue staining, adjacent to the implant surface in all samples. After two weeks, all evaluated surfaces presented peri-implant bone healing with different bone and BIC volumes. The Epikut Plus ${ }^{\circledR}$ with HAnano ${ }^{\circledR}$ coating group showed large trabeculae of neoformed bone between the implant threads and islands of bone debris in contact with the trabecular bone. Several areas of 

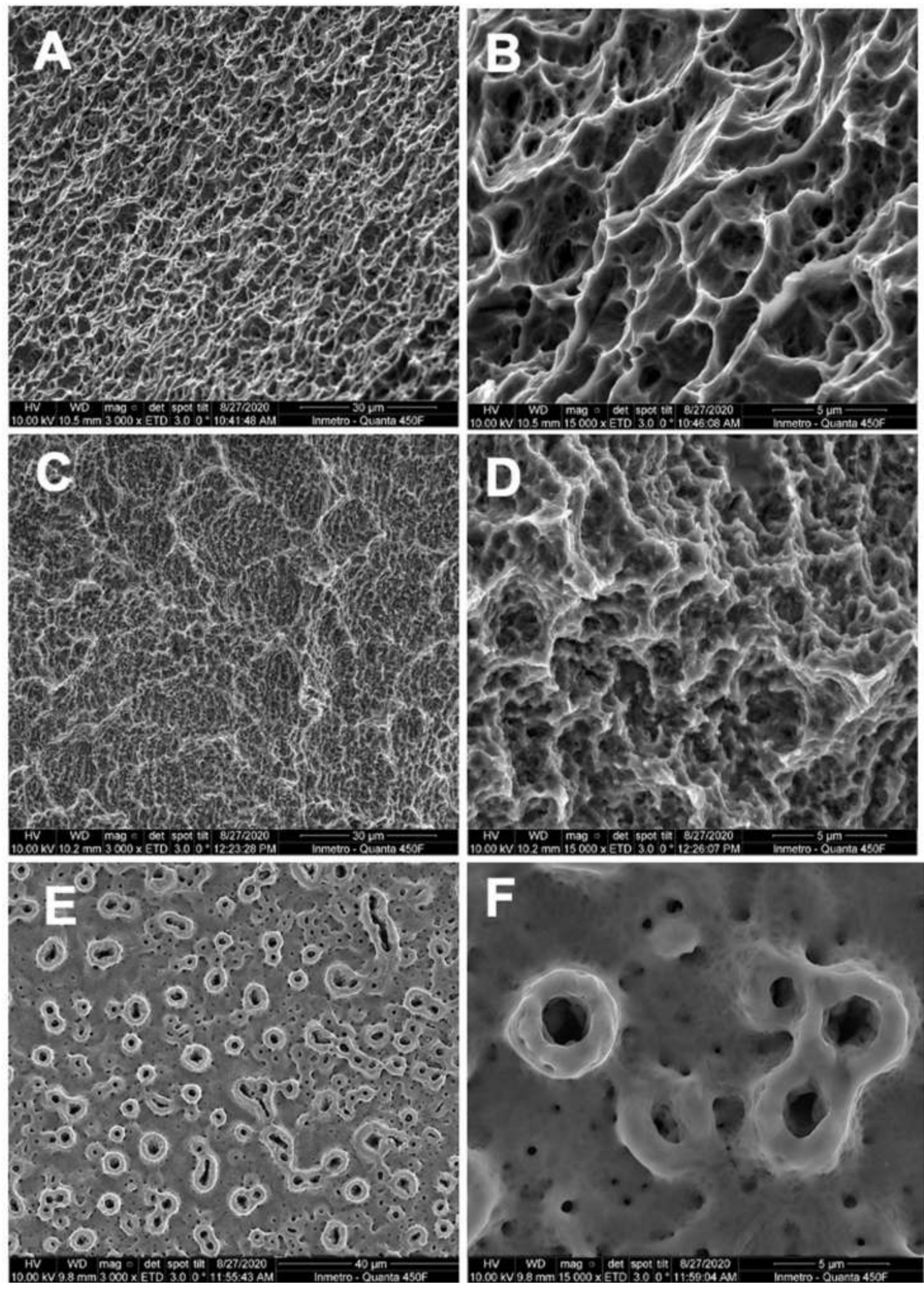

Figure 3 Scanning electron microscopy (SEM) micrographs of implants surface. (A and B) Hanano; (C and D) SLActive, and (E and F) TiUnite. (A, C and E) at 3000x magnification (scale bar $=30 \mu \mathrm{m}$ ) and $(\mathbf{B}, \mathbf{D}$ and $\mathbf{F}) \quad 15,000 \times$ magnification (scale bar $=5 \mu \mathrm{m}$ ).

direct BIC were observed. The $\mathrm{BLX}^{\circledR}$ with SLActive ${ }^{\circledR}$ surface presented a similar degree of bone volume, less extensive trabeculae, bone debris between the threads, and evident BIC areas. The NobelActive ${ }^{\circledR}$ with the TiUnite surface showed bone trabeculae permeating the implant surface at a lower volume than either the nanoHA or SLActive surfaces but with a similar BIC area (Figure 6).
After four weeks, newly formed bone around the implants was clearly apparent. Moreover, a minimum amount of connective tissue was observed in all groups (Figure 7). Using polarization light microscopy, the general orientation of fibers could easily be seen when using a compensator crystal $(\lambda=551 \mathrm{~nm})$. In Figure 8 , the blue coloring indicates that fibers are parallel to the higher refraction index of the compensator. 


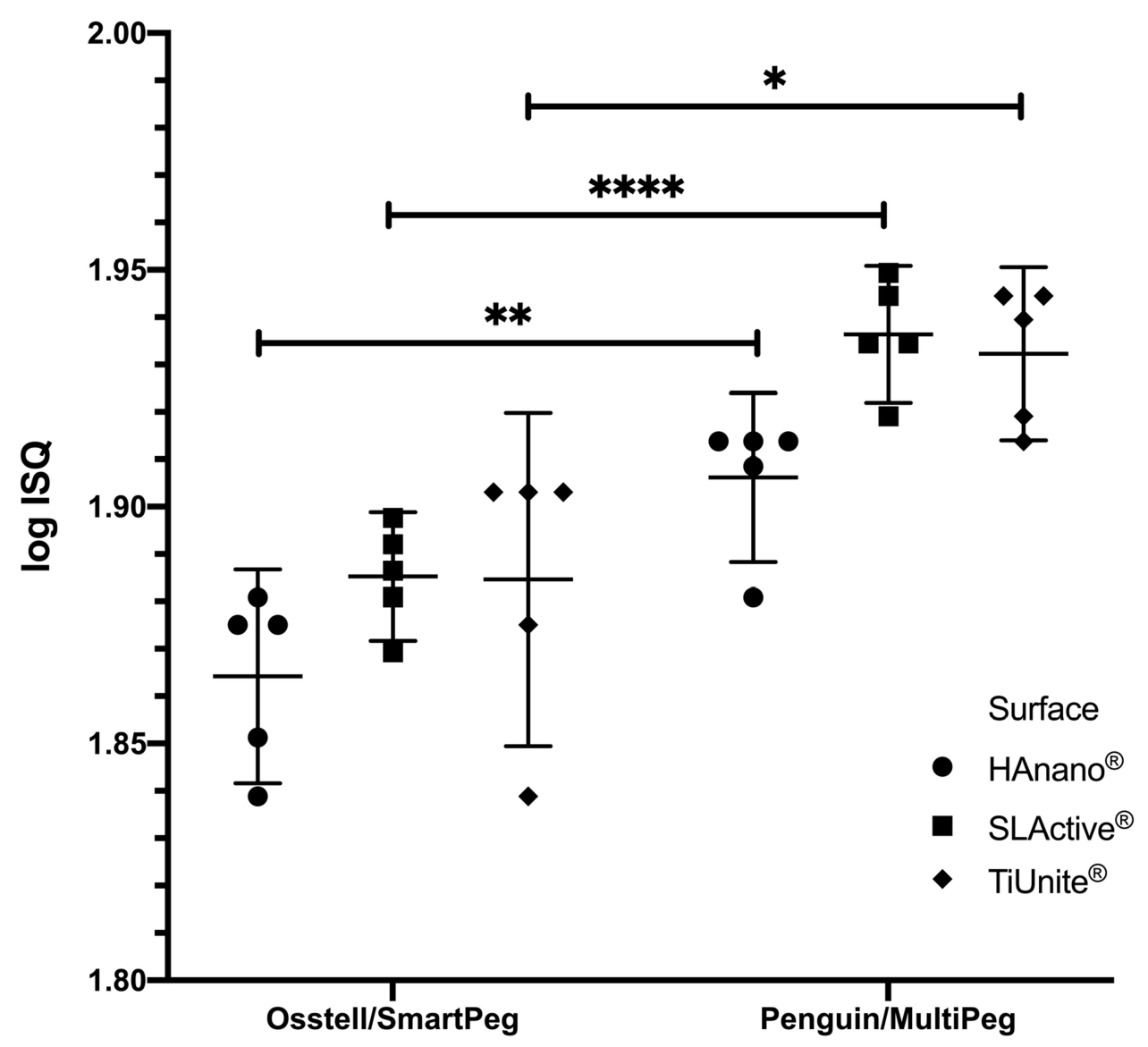

Device for ISQ Analysis

Figure 4 Implant stability quotient (ISQ) values of different implant surfaces. The devices and transducers grouping used were Osstell/Smart Peg (measured as implant stability quotient, ISQ) and Penguin/Multi Peg (measured as resonance frequency analysis, RFA). The graphic shows the distribution of all point values for different surfaces (HAnano, SLActive and TiUnite) with different devices and transducers grouping $(n=5)$. After the normality test (Shapiro-Wilk), the values were transformed in LOG (Y). The groups were submitted to statistical analysis of Two-way ANOVA and Tukey post-test to evaluate the differences between different surfaces with the same device/transducer ( $p<0.05$ ). The Student's $t$-test was applied to assess the differences between the device/transducer at the same implant surface $(p<0.05) ; *(p<0.05)$, ${ }^{* *}(p<0.01)$, and $\left.* * * * * 0.0001\right)$.

\section{$\mathrm{BIC}$}

BIC significantly increased in a time-dependent fashion in all groups tested $(\mathrm{p}<0.05)$ being higher than $80 \%$. However, at each experimental time point, no statistical difference in $\mathrm{BIC}$ $(p>0.05)$ was observed between the experimental groups (Figure 9) (Supplementary Table 2)

\section{Bone Area Fraction Occupancy}

Histomorphometric analysis revealed clearly that all groups experienced a subsequent percental gain in new bone formation (Figure 10). There were no significant differences between the percentage of new bone formation at the implant interface between groups after two or four weeks $(p>0.05)$. Over time, the percentage of new bone formation increased at the interface and the surrounding tissue occupying around $60 \%$ of the analyzed area (Supplementary Table 2).

\section{Discussion}

With the development of nanotechnology, nanostructured HA surfaces are being recognized as promising to achieve rapid osseointegration in low-density bone, which is the main persisting challenge in implant dentistry. Thus, it is believed that the use of HA coatings on metallic implants would improve both the bone strength and speed of rehabilitation of patients by decreasing the time from implant insertion to receipt of the final prosthesis mainly in the posterior area of the maxilla where there the highest rate of failure exists due to progressive bone loss. ${ }^{9}$ Surface topography from the micro- to the nanoscale profoundly influences the bone cells attachment and osseointegration ${ }^{37-39}$ and the rough implant surfaces achieved by HA coatings offer osteoconductive properties ${ }^{40}$ due to increased cell adhesion. 


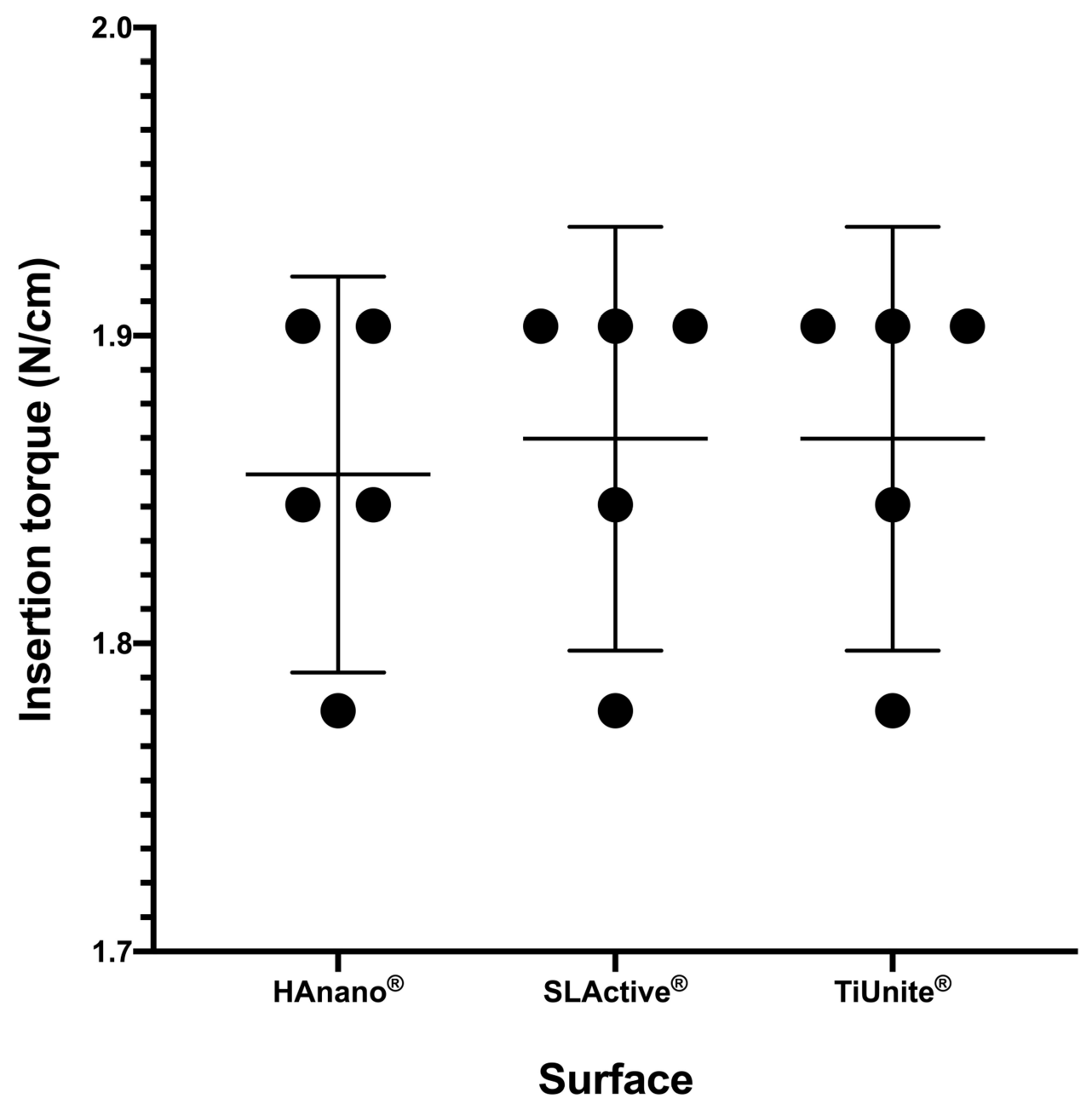

Figure 5 Insertion torque values $(\mathrm{N} / \mathrm{cm})$ of different implant surfaces $\left(H A n a n o^{\circledR}\right.$, SLActive $^{\circledR}$ and TiUnite $\left.{ }^{\circledR}\right)$. The graphic shows the mean values and the confidence interval at $95 \%$ of different groups $(n=5)$, the values were transformed in LOG $(Y)$. The groups were submitted to statistical analysis of one-way ANOVA and Tukey post-test to evaluate the differences between surfaces $(p<0.05)$. There were no differences in the insertion torque between implant surfaces.

Surface interaction and changes at the implant-cell interface result in diverse cellular responses. Understanding intracellular signaling involved in the mechanisms of osteoblast adhesion, proliferation, and differentiation on dental implants is fundamental for the successful osseointegration. The first step in this response to implants involves the adsorption of specific proteins, lipids, sugar, and ions, establishing an organic coating responsible for guiding surrounding cell performance leading to activation of specific genes. ${ }^{41}$ A previous in vitro study has shown that HAnano-blasted titanium surface improved wettability and transformed the implant surface to super-hydrophilic $\left(<4^{\circ}\right)$. This increased wettability facilitates the attachment process of bone cells to the implant surface, thereby improving the implant's integration. ${ }^{42}$ HAnano surface promoted increased cell proliferation, viability and cell spreading as well as type I collagen and osteopontin secretion favoring the early events of osseointegration. ${ }^{43}$
In this preclinical study, we compared the osseointegration performance of a new nanostructured HA coating (Epikut Plus ${ }^{\circledR}$, S.I.N. Implant System, Sao Paulo, Brazil) to a recently launched implant with hydrophilic SLActive ${ }^{\circledR}$ surface (BLX ${ }^{\circledR}$, Straumann, Basel, Switzerland), and the well-known macrogeometry with highly crystalline and enriched TiUnite ${ }^{\circledR}$ surface (NobelActive ${ }^{\circledR}$, Nobel Biocare, Götborg, Sweden).

In general, all histological and biomechanical evaluations suggested no significant difference between the three surface modifications with respect to successful osseointegration. Given the plan to conduct this in vivo study on low-density bone, sheep ilium was chosen as the model for implantation.

The sheep model is considered to be suitable for biomedical research due to the similarities between sheep and humans regarding weight, joint structure, bone tissue, and bone 

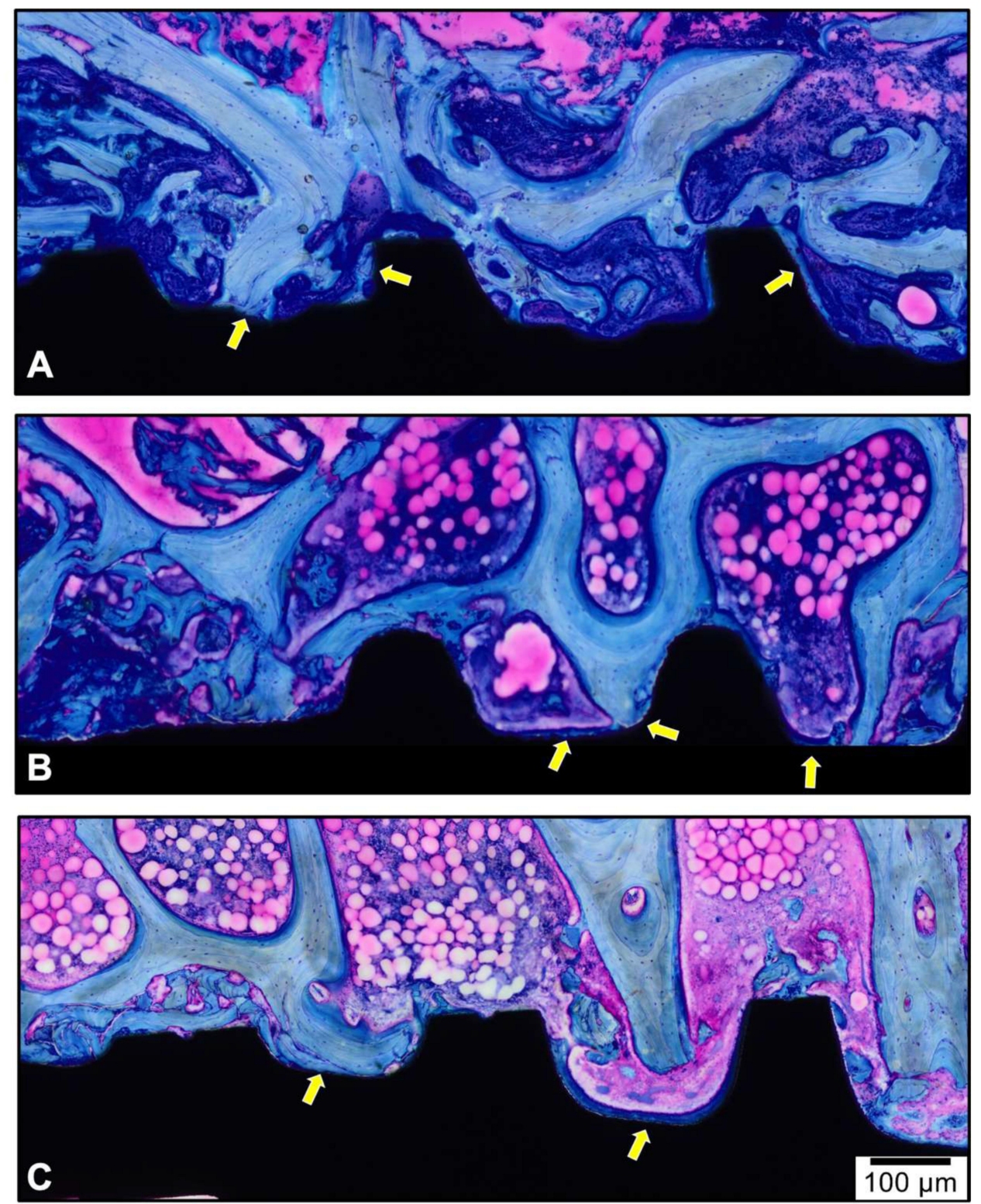

Figure 6 Representative photomicrographs of wound healing to different implant surfaces 14 days after implantation. (A) HAnano ${ }^{\circledR}$, (B) SLActive ${ }^{\circledR}$, and (C) TiUnite ${ }^{\circledR}$. Observe the three most coronally situated implant's threads that were located in the cancellous bone. The yellow arrows represent regions of bone-implant contact. Stain:

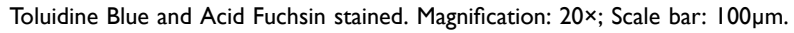

regeneration. $^{28,44}$ It also presents unique advantages such as bone composition, metabolism, remodeling, and regeneration time as compared with other experimental animal models. ${ }^{43}$ Previous studies of dental-implant designs and surface have used sheep, ${ }^{30,33-36,45}$ rabbits, ${ }^{4,20,46}$ and $\operatorname{dogs}^{47-49}$ as animal models. The most used sites in these animals are the jaw ${ }^{47,48}$ or tibia ${ }^{49}$ in dogs; the tibia ${ }^{4,20,46,50}$ in rabbits; and the tibia, ${ }^{34,35}$ iliac crest, ${ }^{30,33,36,45}$ and mandible ${ }^{51}$ in sheep. The iliac crest site offers the advantages of bone characteristics, the absence of postoperative morbidity, and the ability to conduct a high number of implants test simultaneously; however, although the iliac crest exhibits low bone density, the cortical is thicker relative to the thin cortical of the posterior region of the maxilla, which also shows low bone density. Previous studies$30,33,36,45$ that used sheep models have reported that the animals were euthanized at the end of the experiments; in our study, all animals were kept alive and healthy.

The insertion torque value is a direct measure of the bone's cutting resistance during implant insertion surgery. It is a mechanical parameter that can be influenced by the surgical procedure and implant design and is reliant on the bone quality. Here, all tested implants displayed an insertion torque value of between 60 and $80 \mathrm{~N} / \mathrm{cm}$ (min and max); notably, these high values are probably due to the resistance 

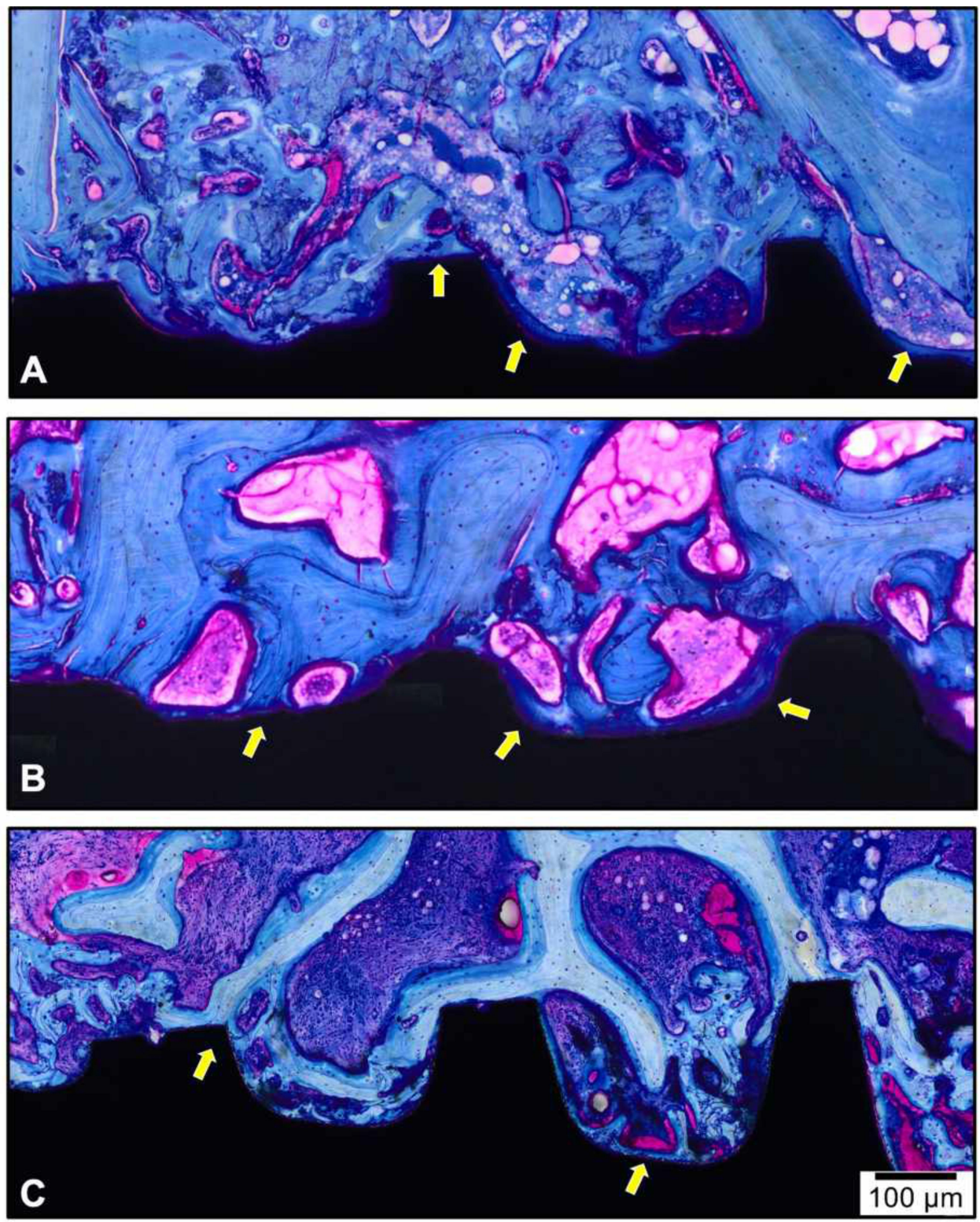

Figure 7 Representative photomicrographs of wound healing to different implant surfaces 28 days after implantation. (A) HAnano ${ }^{\circledR}$, (B) SLActive ${ }^{\circledR}$ and $\left(\right.$ C) TiUnite ${ }^{\circledR}$. Observe the three most coronally situated implant's threads that were located in the cancellous bone. The yellow arrows represent regions of bone-implant contact. Stain: Toluidine Blue and Acid Fuchsin. Magnification: 20x; Scale bar: 100 $\mathrm{mm}$.

of the thicker cortical bone of the iliac crest region of the animal. In another study using sheep, a low value of insertion torque was observed in all groups $(<21 \mathrm{~N} / \mathrm{cm})$, but the experimental implants used were characterized by a reduced thread profile that may have contributed to the low insertion torque values recorded. ${ }^{44}$ Also, in this study, we confirmed the lack of effect of the implant surface on the insertion torque according to previous study. ${ }^{52}$

Primary stability is defined as the absence of movement following intraosseous insertion of the implant. RFA is one of the most commonly used methods to quantitatively evaluate the primary stability of implants This analysis provides information regarding the stiffness of the bone-implant union and the results are recorded as the implant stability quotient. The present study is in agreement with findings of previous randomized clinical trials reporting acceptable primary stability with mean ISQ values of above $75 \mathrm{~N} / \mathrm{cm}$ in humans. ${ }^{53}$ The bone density, implant size and macro-scale geometry of the implant body greatly affect the ISQ values and, as we used the same implant size and receptor area, similar levels of ISQ between the evaluated groups were confirmed. ${ }^{54} \mathrm{~A}$ clinical 


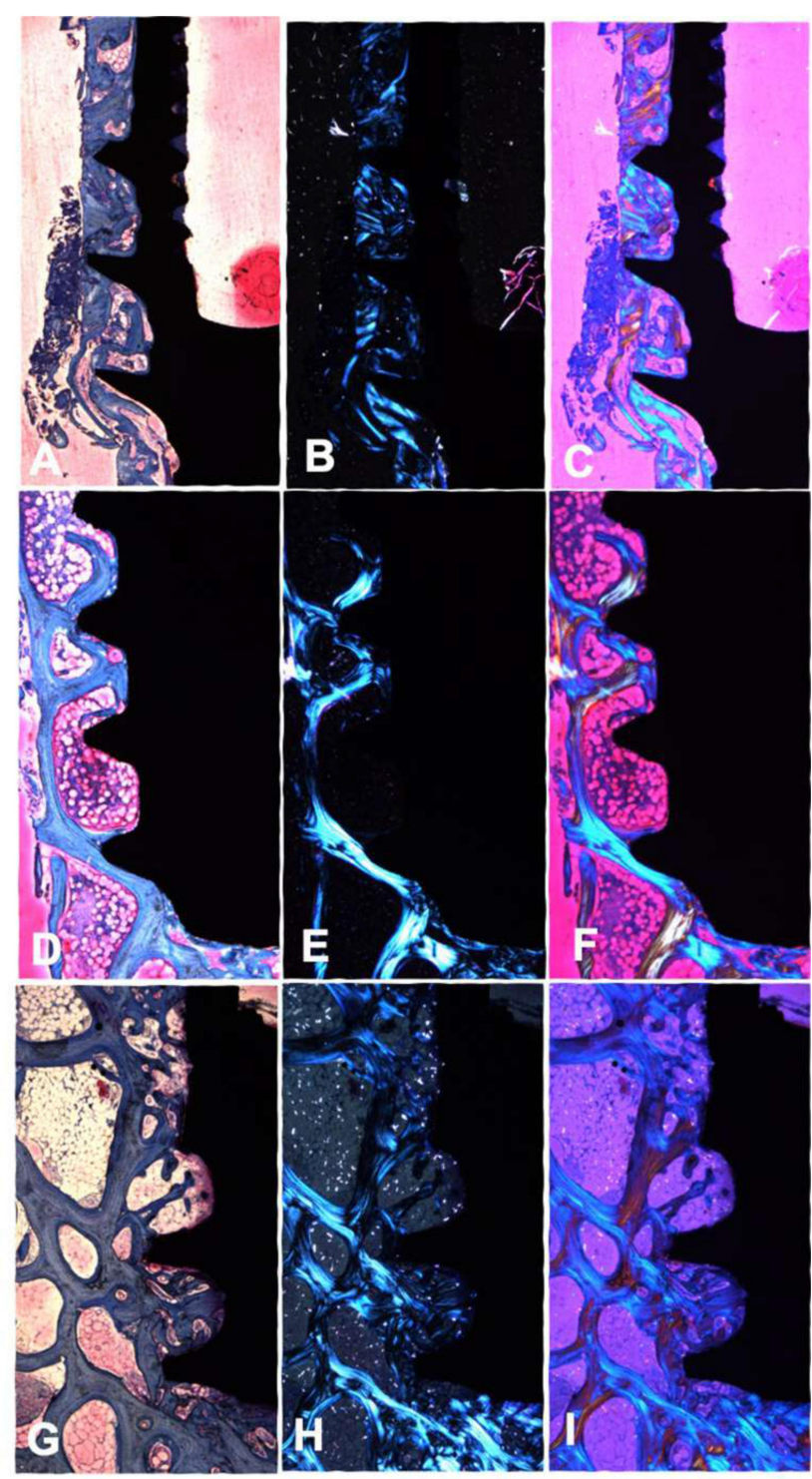

Figure 8 Polarization light microscopy. (A-C) HAnano ${ }^{\circledR}$ group; (D-F) SLActive ${ }^{\circledR}$ group, and (G-I) TiUnite ${ }^{\circledR}$ group. (A, D and $\mathbf{G}$ ) bright filed microscopy; (B, E and H) Polarization light microscopy; (C, F and I) polarization light microscopy with compensator crystal $(\lambda=55 \mathrm{Im})$. The general orientation of bone collagen fibers is easily seen when using polarization light microscopy. Blue in the figure means that fibers are parallel to the higher refraction index of the compensator.

study using tapered implants with a wide thread in the posterior region of maxilla reported a mean ISQ value of $53.66( \pm 12.04),{ }^{55}$ which is very close to our results.

The present study evaluated the resonance frequencies immediately after the implant's installation using two different devices (Osstell ${ }^{\circledR}$ and Penguin ${ }^{\circledR}$ ) and two magnetic transductors $\left(\right.$ SmartPeg $^{\circledR}$ and MulTipeg ${ }^{\circledR}$ ), respectively. We observed statistical differences between the two devices, with the highest values recorded when using the MulTipeg ${ }^{\circledR}$ transducer in combination with the Penguin ${ }^{\circledR}$ device. These results were different from those in the study by Bural et $\mathrm{al}^{57}$ who evaluated the primary stability using the same devices and transducers but observed that the results were discretely higher in the Osstell ${ }^{\circledR}$ group; however, different from in our study, these authors performed the test in an ex vivo model. In our study, the resonance frequency was only evaluated on the day of implant installation; we did not evaluate after the experimental periods to limit any kind of damage caused by the insertion torque of the transductors into the implant and avoid impairing the histological and histomorphometric evaluations of the implant-bone interface.

Elsewhere, a recent systematic review by Lages et $\mathrm{al}^{58}$ found no correlation existed between insertion torque and primary stability, suggesting that a high insertion torque does not necessarily correspond with a high ISQ value. In our study, we recorded high levels of insertion torque and primary stability.

Our results of BIC showed no statistical difference among the three groups in the same experimental period. All groups experienced a constant increase in trabecular bone fixation to the implant surface from two to four weeks, which corroborate data from a previous study which used the SLActive ${ }^{\circledR}$ and TiUnite ${ }^{\circledR}$ surfaces in the same animal/site model. ${ }^{30}$

The bone area fraction occupancy increased from 2 to 4 weeks, but without significative difference between the HAnano $^{\circledR}$, SLActive ${ }^{\circledR}$ to TiUnite ${ }^{\circledR}$. Our results corroborate with those of previous studies assessing HA-coated implants in rabbit tibia after two weeks, ${ }^{59}$ in dogs' sockets after four weeks, ${ }^{60}$ and in the iliac crests of goats after four weeks. ${ }^{61}$ In all these studies, the HA biomimetic coating was able to shorten the healing period of the implants by increasing the implant-bone interaction. Our BIC and BAFO values for HA coating results were similar to those of Van Oirschot et $\mathrm{al}^{61}$ who obtained values of $57.5 \%( \pm 8.5 \%)$ for BIC and $43.6 \%( \pm 9 \%)$ for BAFO in a study in iliac crests of goats after four weeks. Lee et al presented similar results for BAFO and BIC of $44.94 \%$ ( \pm $17.69 \%)$ and $77.28 \%$ ( $\pm 11.22 \%)$ after four weeks in dogs as compared with our study, where the values were $65.53 \%( \pm 6.22 \%)$ and $82.27 \%( \pm 3.38 \%)$.

\section{Conclusion}

The three implant designs and improved surfaces proved comparable osseointegration at the early stages of lowdensity bone repair in the sheep model. 


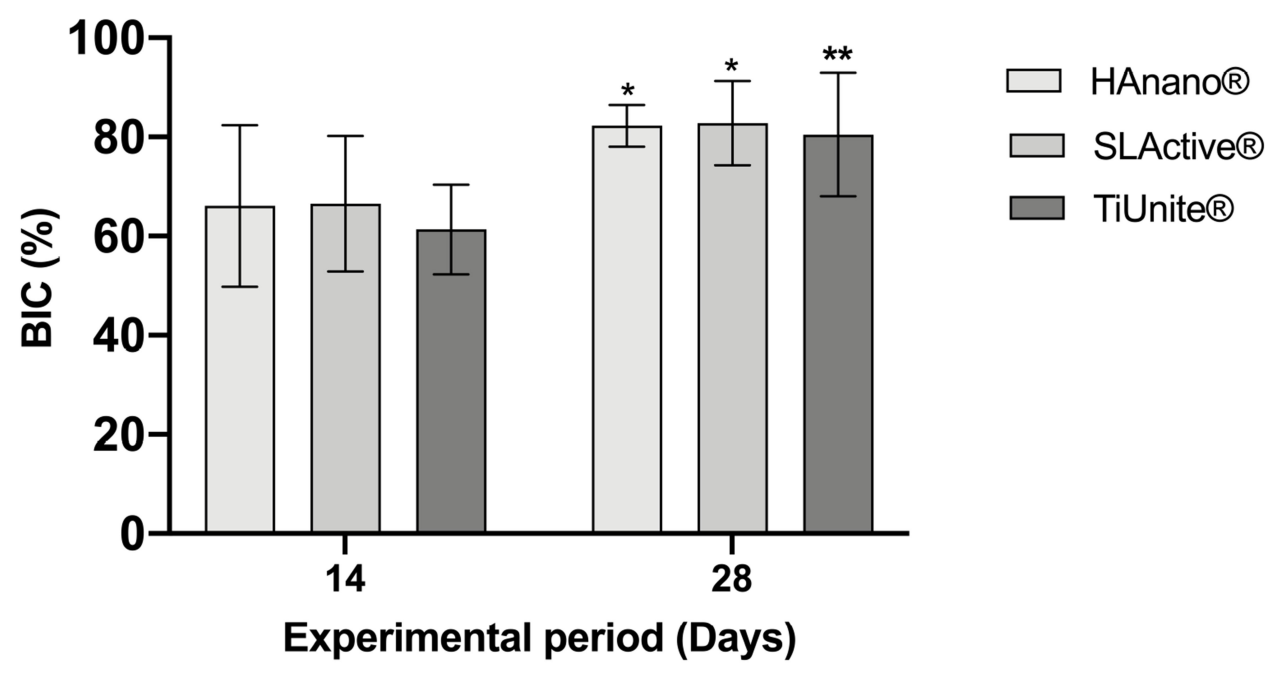

Figure 9 Bone-implant contact (BIC) percentage in the HAnano ${ }^{\circledR}$, SLAactive ${ }^{\circledR}$, and TiUnite ${ }^{\circledR}$ surfaces groups, 14 and 28 days after implantation. The results are presented as a mean \pm confidence interval $(n=5)$. After the normality test (Shapiro-Wilk), the groups were submitted to statistical analysis of One-way ANOVA and Tukey post-test $(p<0.05)$ to evaluate the differences between different surfaces at the same experimental time point. The Student's $t$-test was applied to assess the differences between the same surface groups at different time points $(p<0.05)$, represents by the $(*, p=0.02),(* * ; p=0.008)$. There were no differences in the BIC between implant surfaces at the same time point.

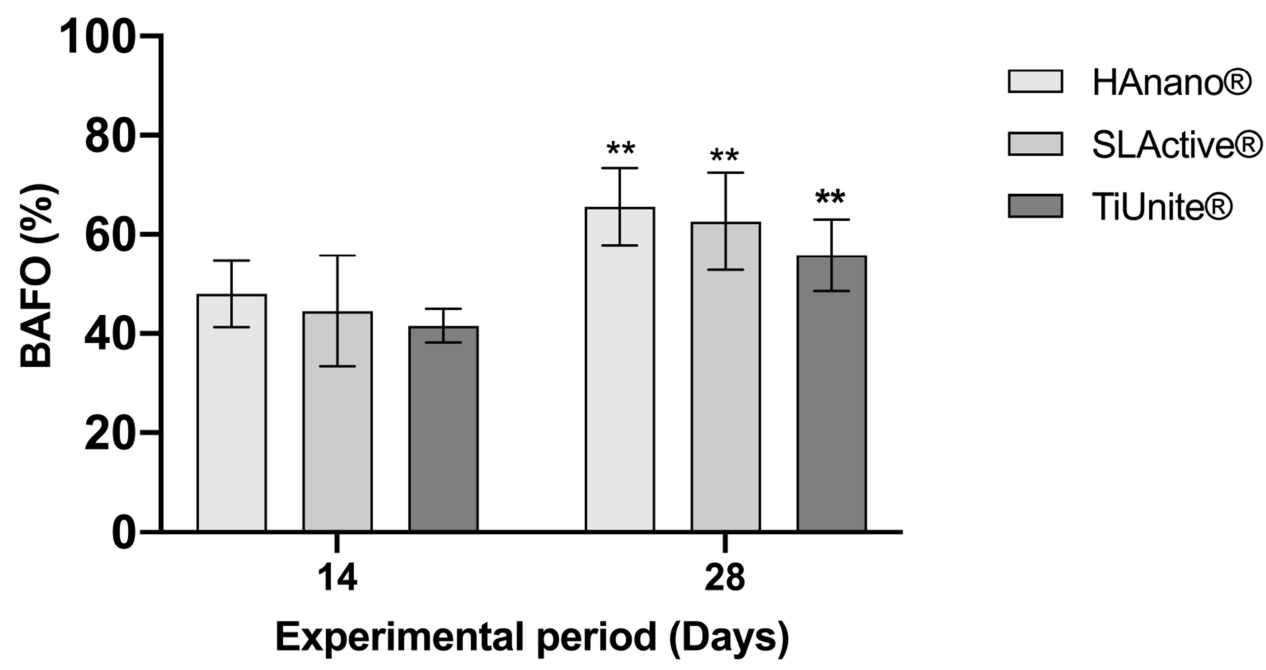

Figure 10 Bone area fraction occupancy (BAFO) percentage in the HAnano ${ }^{\circledR}$, SLAactive ${ }^{\circledR}$ and TiUnite ${ }^{\circledR}$ surfaces groups, 14 and 28 days after implantation. The results are presented as a mean \pm confidence interval $(n=5)$. After the normality test (Shapiro-Wilk), the groups were submitted to statistical analysis of One-way ANOVA and Tukey post-test $(p<0.05)$ to evaluate the differences between different surfaces at the same experimental time point; represents by horizontal bars. The Student's $t$-test was applied to assess the differences between the same surface groups at different experimental time points $(p<0.05)$, represents by the (**; $p$ ranging from 0.001 to 0.009$)$. There were no differences in the BAFO between implant surfaces at the same time point.

\section{Acknowledgments}

The authors wish to thank the staff of the SEM Laboratory (INMETRO), and Prof Marcos Farina (UFRJ) for the polarization light microscopy.

\section{Disclosure}

This study was partially financed by S.I.N. Implant System, Sao Paulo, Brazil, but the company had no influence in the design, execution and analysis of the results.
The authors report no other potential conflicts of interest for this work.

\section{References}

1. Simonis P, Dufour T, Tenenbaum H. Long-term implant survival and success: a 10-16-year follow-up of non-submerged dental implants. Clin Oral Implants Res. 2010;21(7):772-777. doi:10.1111/j.16000501.2010.01912.x

2. Lekholm U, Zarb G. Patient selection and preparation. In: Branemark PI, Zarb G, Albrektsson T, editors. Tissue-Integrated Prosthesis. Chicago: Quintessence Publishing Co; 1985:199-211. 
3. Vasak C, Busenlechner D, Schwarze UY, et al. Early bone apposition to hydrophilic and hydrophobic titanium implant surfaces: a histologic and histomorphometric study in minipigs. Clin Oral Implants Res. 2014;25(12):1378-1385. doi:10.1111/clr.12277

4. Aldosari A, Anil S, Alasqah M, Al Wazzan KA, Al Jetaily SA, Jansen JA. The Influence of implant geometry and surface composition on bone response. Clin Oral Implants Res. 2014;25(4):500-505.

5. Yin C, Zhang Y, Cai Q, et al. Effects of the micro-nano surface topography of titanium alloy on the biological responses of osteoblast. J Biomed Mater Res A. 2017;105A(3):757-769. doi:10.1002/ jbm.a.35941

6. Nicholson JW. Titanium alloys for dental implants: a review. Prosthesis. 2020;2(2):100-116. doi:10.3390/prosthesis2020011

7. Resende RFB, Sartoretto SC, Uzeda MJ, et al. Randomized controlled clinical trial of nanostructured carbonated hydroxyapatite for alveolar bone repair. Materials. 2019;12(22):3645-3658. doi:10. 3390/ma12223645

8. Uzeda MJ, de Brito Resende RF, Sartoretto SC, Alves ATNN, Granjeiro JM, Calasans-Maia MD. Randomized clinical trial for the biological evaluation of two nanostructured biphasic calcium phosphate biomaterials as a bone substitute. Clin Implant Dent Relat Res. 2017;19(5):802-811. doi:10.1111/cid.12516

9. Ong JL, Chan A. Review of hydroxyapatite and its use as a coating in dental implants. Crit Rev Biomed Eng. 2017;45(1-6):411-451. doi:10.1615/CritRevBiomedEng.v45.i1-6.160

10. Luvizuto ER, Tangl S, Zanoni G, et al. The effect of BMP-2 on the osteoconductive properties of b-tricalcium phosphate in rat calvaria defects. Biomaterials. 2011;32(15):3855e3861. doi:10.1016/j.biomaterials.2011.01.076

11. Mourão CFAB, Lourenço ES, Nascimento JRB, et al. Does the association of blood-derived growth factors to nanostructured carbonated hydroxyapatite contributes to the maxillary sinus floor elevation? A randomized clinical trial. Clin Oral Investig. 2019;23(1):369379. doi:10.1007/s00784-018-2445-7

12. Soriano-Souza CA, Rossi AL, Mavropoulos E, et al. Chlorhexi-dineloaded hydroxyapatite microspheres as an antimicrobial delivery system and its effect on in vivo osteoconductive properties. $J$ Mater Sci Mater Med. 2015;26:166. doi:10.1007/s10856-015-5505-4

13. Calasans-Maia MD, Barboza-Junior CAB, Soriano-Souza CA, et al. Microspheres of alginate encapsulated minocycline-loaded nanocrystalline carbonated hydroxyapatite: therapeutic potential and effects on bone regeneration. Int $J$ Nanomedicine. 2019;14:4559-4571. doi:10.2147/IJN.S201631

14. Soriano-Souza C, Valiense H, Mavropoulos E, et al. Doxycycline containing hydroxyapatite ceramic microspheres as a bone-targeting drug delivery system. J Biomed Mater Res. 2019:1-12. doi:10.1002/jbm.b.34484.

15. Maté Sánchez de Val JE, Calvo-Guirado JL, Gómez-Moreno G, Gehrke S, Mazón P, De Aza PN. Influence of hydroxyapatite granule size, porosity, and crystallinity on tissue reaction in vivo. Part B: a comparative study with biphasic synthetic biomaterials. Clin Oral Implants Res. 2018;29(11):1077-1084. doi:10.1111/clr.12880

16. Wheeler SL. Eight-year clinical retrospective study of titanium plasma-sprayed and hydroxyapatite-coated cylinder implants. Int $J$ Oral Maxillofac Implants. 1996;11:340-350.

17. Zablotsky MH. Hydroxyapatite coatings in implant dentistry. Implant Dent. 1992;1(4):253-257. doi:10.1097/00008505-199200140-00004

18. Jung J-H, Kim S-Y, Yi Y-J, Lee B-K, Kim Y-K. Hydroxyapatitecoated implant: clinical prognosis assessment via a retrospective follow-up study for the average of 3 years. $J$ Adv Prosthodont. 2018;10(2):85-92. doi:10.4047/jap.2018.10.2.85

19. Sugiyama T, Miake Y, Yajima Y, Yamamoto K, Sakurai K. Surface observation of thin hydroxyapatite-coated implants at 80 months after insertion. J Oral Implantol. 2011;37(2):273-278. doi:10.1563/AAIDJOI-D-09-00113.1

20. Meirelles L, Melin L, Peltola T, et al. Effect of hydroxyapatite and titania nanostructures on early in vivo bone response. Clin Implant Dent Relat Res. 2008;10:245-254. doi:10.1111/j.1708-8208.2008.00089.x
21. Martinez EF, Ishikawa GJ, Lemos AB, Bezerra FJB, Sperandio M, Napimoga MH. Evaluation of a titanium surface treated with hydroxyapatite nanocrystals on osteoblastic cell behavior: an in vitro study. Int $J$ Oral Maxillofac Implants. 2018;33(3):597-602. doi:10.11607/jomi.5887

22. Miao X, Wang D, Xu L, et al. The response of human osteoblasts, epithelial cells, fibroblasts, macrophages and oral bacteria to nanostructured titanium surfaces: a systematic study. Int J Nanomedicine. 2017;12:1415-1430. doi:10.2147/IJN.S126760

23. Pang X, Huang Y. Physical properties of Nano-HAs/ZrO2 coating on surface of titanium materials used in dental-implants and its biological compatibility. J Nanosci Nanotechnol. 2012;12(2):902-910. doi:10.1166/jnn.2012.5666

24. Kilkenny C, Brown WJ, Cuthill IC, Emerson M, Altman DG. Improving bioscience research reporting: the ARRIVE guidelines for reporting animal research. PLoS Biol. 2010;8(6):e1000412. doi:10.1371/journal.pbio. 1000412

25. Smith AJ, Clutton RE, Lilley E, Hansen KEA, Brattelid T. PREPARE: guidelines for planning animal research and testing. $L a b$ Anim. 2018;52(2):135-141. doi:10.1177/0023677217724823

26. National Research Council. Guide for the Care and Use of Laboratory Animals. 8th, edn. Washington (DC); National Academies Press (US): 2011. doi: 10.17226/12910

27. DBCA. Diretriz Brasileira para o Cuidado e a Utilização de Animais para Fins Científicos e Didáticos. Brasília: Ministério da Ciência, Tecnologia e Inovação Conselho Nacional de Controle de Experimentação Animal - CONCEA; 2013. Available from: http:// www.cobea.org.br/arquivo/download?ID_ARQUIVO=20. Accessed October 22, 2020.

28. NC3Rs Reporting Guidelines Working Group. Animal research: reporting in vivo experiments: the ARRIVE guidelines. $J$ Physiol. 2010;588(14):2519-2521. doi:10.1113/jphysiol.2010.192278

29. Lansdowne JL, Devine D, Eberli U. Characterization of a sheep bilateral critical sized bone defect iliac wing model to examine treatment modalities based on bone tissue engineering. Biomed Res Int. 2014;2014:1-7. doi:10.1155/2014/250958

30. Ernst S, St€ubinger S, Sch€upbach P, et al. Comparison of two dental implant surface modifications on implants with same macrodesign: an experimental study in the pelvic sheep model. Clin Oral Implants Res. 2015;26(8):898-908. doi:10.1111/clr.12411

31. Sealed Envelope Ltd. Power calculator for continuous outcome superiority trial; 2012. Available from: https://www.sealedenvelope. com/power/continuous-superiority/. Accessed Sep 01, 2020.

32. Charan J, Kantharia ND. How to calculate sample size in animal studies? J Pharmacol Pharmacother. 2013;4:303-306. doi:10.4103/ 0976-500X.119726

33. Ferguson SJ, Langhoff JD, Voelter K, etal. Biomechanical comparison of different surface modifications for dental implants. Int J Oral Maxillofac Implants. 2008;23:1037-1046.

34. Sartoretto SC, Alves ATNN, Zarranz L, Jorge MZ, Granjeiro JM, Calasans-Maia MD. Hydrophilic surface of Ti6Al4V-ELI alloy improves the early bone apposition of sheep tibia. Clin Oral Implants Res. 2017;28(8):893-901. doi:10.1111/clr.12894

35. Sartoretto SC, Calasans-Maia JA, da Costa YO, Louro RS, Granjeiro JM, Calasans-Maia MD. Accelerated healing period with hydrophilic implant placed in sheep tibia. Braz Dent J. 2017;28(5):559-565. doi:10.1590/0103-6440201601559

36. Yoo D, Marin C, Freitas G, et al. Surface characterization and in vivo evaluation of dual acid-etched and grit-blasted/acid-etched implants in sheep. Implant Dent. 2015;24:256-262. doi:10.1097/ID.0000000000000248

37. Wennerberg A, Albrektsson T. Effects of titanium surface topography on bone integration: a systematic review. Clin Oral Implants Res. 2009;20 (Suppl 4):172-184. doi:10.1111/j.1600-0501.2009.01775.x

38. Gittens RA, McLachlan T, Olivares-Navarrete R, et al. The effects of combined micron-/submicron-scale surface roughness and nanoscale features on cell proliferation and differentiation. Biomaterials. 2011;32(13):3395-3403. doi:10.1016/j.biomaterials.2011.01.029 
39. Gittens RA, Olivares-Navarrete R, McLachlan T, et al. Differential responses of osteoblast lineage cells to nanotopographically-modified, microroughened titanium-aluminum-vanadium alloy surfaces. Biomaterials. 2012;33(35):8986-8994. doi:10.1016/j.biomaterials.2012. 08.059

40. Qadir M, Li Y, Wen C. Ion-substituted calcium phosphate coatings by physical vapor deposition magnetron sputtering for biomedical applications: a review. Acta Biomater. 2019;89:14-32. doi:10.1016/j. actbio.2019.03.006

41. Amani H, Arzaghi H, Bayandori M, Dezfuli AS, Pazoki-Toroudi H, Shafiee A. Controlling cell behavior through the design of biomaterial surfaces: a focus on surface modification techniques. Adv Mater Interfaces. 2019;6(13):1900572. doi:10.1002/admi.201900572

42. Bezerra F, Ferreira MR, Fontes GN, et al. Nano hydroxyapatiteblasted titanium surface affects pre-osteoblast morphology by modulating critical intracellular pathways. Biotechnol Bioeng. 2017;114 (8):1888-1898. doi:10.1002/bit.26310.

43. Martinez EF, Ishikawa GJ, Lemos AB, Bezerra FJB, Sperandio M, Napimoga MH. Evaluation of a titanium surface treated with hydroxyapatite nanocrystals on osteoblast cell behavior: an in vitro study. Int J Oral Maxillofac Implants. 2017. doi:10.11607/ jomi.5887.

44. Sartoretto SC, Uzeda MJ, Miguel FB, Nascimento JR, Ascoli F, Calasans-Maia MD. Sheep as an experimental model for biomateria implant evaluation. Acta Ortop Bras. 2016;24(5):262-266. doi:10.1590/1413-785220162405161949

45. Qamheya AHA, Arisan V, Mutlu Z, et al. Thermal oxidation and hydrofluoric acid treatment on the sandblasted implant surface: a histologic histomorphometric and biomechanical study. Clin Oral Implants Res. 2018;29(7):741-755. doi:10.1111/clr.13285

46. Quaranta A, Iezzi G, Scarano A, et al. A histomorphometric study of nanothickness and plasma-sprayed calcium-phosphorous-coated implant surfaces in rabbit bone. J Periodontol. 2010;81(4):556-561. doi:10.1902/jop.2010.090296

47. Alharbi HM, Babay N, Alzoman H, Basudan S, Anil S, Jansen JA. Bone morphology changes around two types of bone-level implants installed in fresh extraction sockets - a histomorphometric study in Beagle dogs. Clin Oral Implants Res. 2014;1-7. doi:10.1111/ clr. 12388

48. Hirakawa Y, Jimbo R, Shibata Y, Watanabe I, Wennerberg A, Sawase T. Accelerated bone formation on photo-induced hydrophilic titanium implants: an experimental study in the dog mandible. Clin Oral Implants Res. 2013;24(Suppl. A100):139-144. doi:10.1111/j.16000501.2011.02401.x

49. Giro G, Tovar N, Marin C, et al. The effect of simplifying dental implant drilling sequence on osseointegration: an experimental study in dogs. Int J Biomater. 2013;6. doi:10.1155/2013/230310

50. Sartoretto SC, Alves ATNN, Resende RFB, Calasans-Maia JA, Granjeiro JM, Calasans-Maia MD. Early osseointegration driven by the surface chemistry and wettability of dental implants. $J$ Appl Oral Sci. 2015;23(3):280-288. doi:10.1590/1678775720140483
51. Shihab OI, Samad AA, Ali HZ, Omer OA, Haider AA. Osseointegration of dental implants without primary stability: an experimental study in sheep. Zanco J Med Sci. 2017;21(1):16141618. doi:10.15218/zjms.2017.011

52. Han J, Lulic M, Lang NP. Factors influencing resonance frequency analysis assessed by Osstell mentor during implant tissue integration: II. Implant surface modifications and implant diameter. Clin Oral Implants Res. 2010;21(6):605-611. doi:10.1111/j.1600-0501. 2009.01909.x

53. Carmo Filho LC, Marcello-Machado RM, Castilhos ED, Del Bel Cury AA, Faot F. Can implant surfaces affect implant stability during osseointegration? A randomized clinical trial. Braz Oral Res. 2018;32:e110. doi:10.1590/1807-3107bor-2018.vol32.0110

54. Sim CP, Lang NP. Factors influencing resonance frequency analysis assessed by Osstell mentor during implant tissue integration: I. Instrument positioning, bone structure, implant length. Clin Oral Implants Res. 2010;21(6):598-604. doi:10.1111/j.1600-0501. 2009.01878.x

55. Sánchez-Siles M, Ilha JB, Ruizc JAF, Alonsod FC. Evaluation of primary stability and early healing of 2 implant macro designs placed in the posterior maxilla: a split-mouth prospective randomized controlled clinical study. J Oral Rehabil. 2019;5:8-15.

56. López-Valverde N, Flores-Fraile J, Ramírez JM, de Sousa BM, Herrero-Hernández S, López-Valverde A. Bioactive surfaces vs. conventional surfaces in titanium dental implants: a comparative systematic review. J Clin Med. 2020;9(7):2047-2073. doi:10.3390/ jcm9072047.

57. Bural C, Dayan C, Geçkili O. Initial stability measurements of implants using a new magnetic resonance frequency analyzer with titanium transducers: an ex vivo study. J Oral Implantol. 2020. doi:10.1563/aaid-joi-D-19-00126

58. Lages FS, Douglas-de Oliveira DW, Costa FO. Relationship between implant stability measurements obtained by insertion torque and resonance frequency analysis: a systematic review. Clin Implant Dent Relat Res. 2018;20(1):26-33. doi:10.1111/ cid. 12565

59. Lukaszewska-Kuska M, Krawczyk P, Martyla A, Hedzelek W, Dorocka-Bobkowska B. Effects of a hydroxyapatite coating on the stability of endosseous implants in rabbit tibiae. Dent Med Probl. 2019;56(2):123-129. doi:10.17219/dmp/103851

60. Lee J, Yoo J-M, Ben Amara H, et al. Bone healing dynamics associated with 3 implants with different surfaces: histologic and histomorphometric analyses in dogs. J Periodontal Implant Sci. 2019;49 (1):25-38. doi:10.5051/jpis.2019.49.1.25

61. Van Oirschot BAJA, Meijer GJ, Bronkhorst EM, Närhi T, Jansen JA, Beucken JJVD. Comparison of different surface modifications for titanium implants installed into the goat iliac crest. Clin Oral Implants Res. 2014;27(2):e57-e67. doi:10.1111/clr.12529
International Journal of Nanomedicine

\section{Publish your work in this journal}

The International Journal of Nanomedicine is an international, peerreviewed journal focusing on the application of nanotechnology in diagnostics, therapeutics, and drug delivery systems throughout the biomedical field. This journal is indexed on PubMed Central, MedLine, CAS, SciSearch ${ }^{\mathbb{R}}$, Current Contents ${ }^{\mathbb{B}} /$ Clinical Medicine,
Journal Citation Reports/Science Edition, EMBase, Scopus and the Elsevier Bibliographic databases. The manuscript management system is completely online and includes a very quick and fair peer-review system, which is all easy to use. Visit http://www.dovepress.com/ testimonials.php to read real quotes from published authors. 